\title{
Grepafloxacin in patients with acute bacterial exacerbations of chronic bronchitis - A question of speed in bacterial killing
}

Jerome J Schentag Pharm D

JI Schentag. Grepafloxacin in patients with acute bacterial exacerbations of chronic bronchitis - A question of speed in bacterial killing. Can J Infect Dis 1998;9(Suppl E):16E-22E.

OBJECTIVE: To characterize the population pharmacokinetics and pharmacodynamics of oral grepafloxacin in patients with acute bacterial exacerbations of chronic bronchitis (ABECB), with particular attention to the speed of bacterial killing. This was possible because the study design incorporated daily cultures of the patients' sputum.

PATIENTS AND METHODS: The study group included 76 patients (43 male, 33 female) between 23 and 81 years of age who were part of a multicentre, randomized, double-blind, dose-response study. Patients were randomly assigned to receive oral regimens of grepafloxacin - 200, 400 or $600 \mathrm{mg}$ - each administered once daily for 14 days. Daily cultures and quantitative Gram stains from serial $24 \mathrm{~h}$ collections of sputum were used to determine the days to eradication of each strain of bacteria. Grepafloxacin plasma concentration profiles were best fit by a pharmacokinetic model with first order absorption following a lag time between administration of the dose and onset of systemic absorption. Pharmacodynamic analysis was performed for three measures of antibacterial response: probability of bacteriological cure and probability of clinical cure, and time to eradication.

RESULTS: All three measures of response were strongly related to the $24 \mathrm{~h}$ area under the inhibitory curve (AUIC) (area under the curve/minimum inhibitory concentration). At an AUIC below of $75 /$ serum inhibiting titre (SIT) $\times 24 \mathrm{~h}$, the percentage probability of clinical cure was $71 \%$; at an AUIC between 75 and 175 , it was $80 \%(\mathrm{P}<0.05)$; and, at an AUIC above 175 , it was $98 \%(\mathrm{P}<0.01)$.

CONCLUSION: The speed of bacterial killing for grepafloxacin in ABECB patients was highly related to AUIC; values below 75 appear inadequate, and values greater than 175 were optimal.

Key Words: Acute bacterial exacerbations of chronic bronchitis, Area under the inhibitory curve, Grepafloxacin, Pharmacodynamics, Pharmacokinetics

La grépafloxacine chez des patients présentant des exacerbations bactériennes aiguës d'une bronchite chronique - Rapidité de l'éradication bactérienne

OBJECTIF : Identifier les propriétés pharmacocinétiques et pharmacodynamiques de la grépafloxacine orale chez des patients souffrant d'exacerbations bactériennes aiguës d'une bronchite chronique (EBABC) en portant une attention particulière à la rapidité de l'éradication des bactéries, ce qui a été facilité par le protocole de l'étude qui prévoyait des cultures quotidiennes des expectorations chez les patients.

PATIENTS ET MÉTHODES : La population étudiée regroupait 76 patients ( 43 hommes, 33 femmes) âgés de 23 à 81 ans

voir page suivante

SUNY, Buffalo Clinical Pharmacokinetics Laboratory, Millard Fillmore Health System, Buffalo, New York USA

Correspondence: Dr IJ Schentag, The Clinical Pharmacokinetics Laboratory, Millard Fillmore Health System, 3 Gates Circle, Buffalo, New York USA 14209. Telephone 716-887-4482,fax 716-887-4566,e-mail jschenta@mfhs.ecu 
qui participaient à une étude multicentrique, randomisée, à double insu, portant sur le lien dose-réponse. Les patients ont été assignés aléatoirement à des schémas thérapeutiques oraux de grépafloxacine (200,400ou 600 mg) administrés chacun une fois par jour pendant 14 jours. Les cultures quotidiennes et les colorations de Gram quantitatives provenant de collections d'expectorations de 24 heures sériées ont servi au calcul du nombre de jours écoulés avant l'éradication de chacune des souches de bactéries. Les profils de concentration plasmatique de grépafloxacine ont été le mieux ajustés par le biais d'un modèle pharmacocinétique qui prévoyait l'effet de premier passage et respectait un délai entre l'administration de la dose et le début de l'absorption systémique. L'analyse pharmacodynamique a été effectuée pour trois paramètres de la réponse antibactérienne : probabilité d'une guérison bactériologique probabilité de guérison clinique et délai d’éradication.

RÉSULTATS : Les trois mesures de la réponse on été en forte corrélation avec les aires sous la courbe inhibitrice (ASCI) de $24 \mathrm{~h}$ (aire sous la courbe/concentration minimale inhibitrice). À une ASCl inférieure à 75/titre sérique inhibiteur (TSI) x $24 \mathrm{~h}$, le pourcentage de probabilité de guérison clinique était de $71 \%$; à une ASCl de 75 à 175 , il s'élevait à $80 \%$ $(p<0,05)$ et à une $\mathrm{ASCl}$ supérieure à 175 , il s'élevait à $98 \%(p<0,01)$.

CONCLUSION : La rapidité d'éradication bactérienne par la grépafloxacine chez les patients présentant des EBABC a été fortement liée à l'ASCI. Les valeurs inférieures à 75 semblent inadéquates et les valeurs supérieures à 175 se sont révélées optimales.

A chievement of an optimal relationship between the pharmacokinetics of fluoroquinolone antibiotics in the patient and the minimum inhibitory concentration (MIC) of the infecting organism in that same patient is predictive of eradication of the invading organism (1-5). Thus far, studies have advanced these principles in patients with nosocomial lower respiratory tract infections (LRTI). In a study of 73 nosocomial LRTI patients given intravenous ciprofloxacin, the optimal area under the curve (AUC) to MIC ratio, AUC: MIC or area under the inhibitory curve (AUIC), was 125, which approximates $80 \%$ of the AUC to be above the MIC value at dosing intervals of every 8 to $12 \mathrm{~h}(1,4)$. When the AUIC was above 125 , a significantly greater number of these patients were cured both microbiologically and clinically. Ciprofloxacin displayed concentration-dependent bacterial killing in patients. Compared with the time of bacterial killing at AUIC values above 125 but less than 250, the time of bacterial eradication at AUIC values exceeding 250 was significantly more rapid $(1,2)$. Nosocomial LRTI patients below the threshold AUIC value of 125 have a microbiological failure rate approaching $70 \%(1)$.

In the early phases of clinical antibiotic development, studies of the AUIC of patient populations given a range of doses can assist in the determination of an optimal dosage for patients with known infecting pathogens. Furthermore, concentrating on the factors that alter the AUIC value in individual patients can explain different outcomes in clinical trial patients. For example, studies in our LRTI patients demonstrate that variability in the clinical and microbiologic response of LRTI patients can result from pronounced interpatient differences in pharmacokinetics. The primary determinants of variability in pharmacokinetics are typically renal function because it is a determinant of AUC and MIC because it varies between organisms, even within the same species.

The AUIC versus outcome principles developed for ciprofloxacin should apply to the new fluoroquinolone antibiotic grepafloxacin (OPC-17116). However, there are some factors unique to this compound that should be studied. Unlike antibiotics of this class that we studied previously, grepafloxacin is not renally excreted to a significant degree. Thus, inter- and intrapatient variability in AUC may be less than or greater than that of antibiotics such as ofloxacin, which is almost en- tirely renally excreted (6), or ciprofloxacin, which is excreted by both pathways (6).

Grepafloxacin is better suited to the treatment of outpatient respiratory tract infections. We measured the AUICs of the new fluoroquinolone in patients with acute bacterial exacerbations of chronic bronchitis (ABECB). ABECB is a highly suitable model for studies of AUIC versus bacterial eradication $(7,8)$. Serial sputum specimens are readily obtainable in these patients. Also, bacterial organisms are found in most patients, and the patients are sufficiently ambulatory to allow frequent returns to the study sites for rigorous blood sampling to characterize the drugs' pharmacokinetics. There has been little study of serial cultures and frequent blood samples in the ABECB population before the present study, so the impact of the disease on either pharmacokinetics or pharmacodynamics was unknown. The generally prevailing opinion that cultures are of little value in $\operatorname{ABECB}(7,9)$ did not discourage this exercise. Rather, the present study seemed an excellent means to determine whether there was a relationship between organism eradication and the outcome of ABECB. It was clearly necessary to culture microbes from patients more frequently to test organism eradication methodology in $A B E C B$ patients. The present report is a summary of our previous study of grepafloxacin in patients with AECB (10).

\section{PATIENTS AND METHODS}

Patient selection and randomization: Data were collected from three prospective clinical trials of grepafloxacin for ABECB. All patients included in this study had frequent sputum cultures and frequent blood samples, the data required for the analysis of the relationship between grepafloxacin pharmacokinetics and pharmacodynamics. Patients included in this study were 18 years of age or more with a diagnosis of chronic bronchial disease, including but not limited to chronic bronchitis, chronic bronchial asthma, asthmatic bronchitis or bronchiectasis. Each enrolled patient had, superimposed on this underlying disease, an acute bacterial bronchial infection characterized by all three of the following: increase in bronchopulmonary symptoms, increase in inflammatory neutrophils in sputum, and sputum Gram stain analysis indicating the absence of contaminating oropharyngeal squamous cells and significant numbers of morphologically distinct bacteria. 


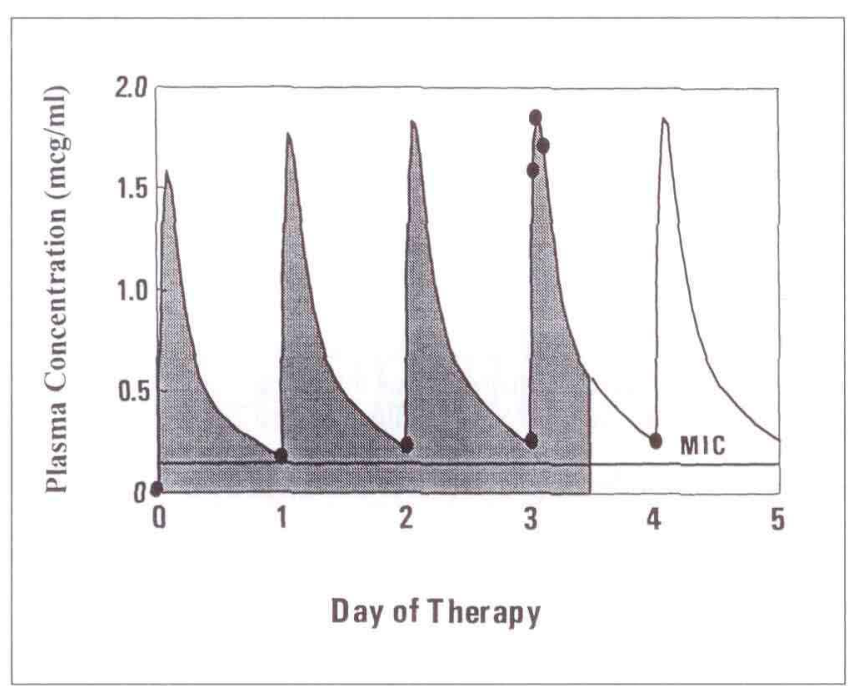

Figure 1) Determination of the area under the inhibitory curve. Iterative two-stage analysis was used to fit a pharmacokinetic model (solid curve) to the observed plasma concentrations (closed circles). The area under the curve from zero to DTE (days to eradication) (shaded region) was determined by numerical integration; in the above example, DTE is 3.5 days. MIC Minimal inhibitory concentration; mcg Micrograms

Patients were excluded if they had a history of allergy to either beta-lactams or fluoroquinolones, if they required hospitalization or parenteral therapy, or if the chest radiograph indicated the presence of a pneumonia. Patients were also excluded if they had evidence of gastrointestinal disease; were taking either oral antacids or sucralfate, which might interfere with the absorption of oral medications (6); had evidence of hepatic disease or renal insufficiency (serum creatinine above $1.5 \mathrm{mg} / \mathrm{dL}$ ); or were concomitantly receiving warfarin or fenbufen.

Study design and sampling procedures: In all three protocols, patients were randomly assigned to receive oral doses of grepafloxacin 200,400 or $600 \mathrm{mg}$ once daily for 14 days. Study drug formulations were grepafloxacin $200 \mathrm{mg}$ or placebo tablets. Patients were treated on an out-patient basis for 14 days with scheduled clinic visits on day 1 ; day 3,4 or 5 ; day 8; day 10,11 or 12 ; and day 14 . On the days on which a clinic visit was scheduled, the patient was instructed to withhold the dose for that day and to bring all remaining study drug to clinic. The dose for that day was taken under observation at the prescribed time.

On clinic days, there was an assessment of the nature and quality of bronchopulmonary signs and symptoms, and vital signs. Blood was collected for hematology and serum chemistries, and determination of trough grepafloxacin concentrations. Sputum was collected quantitatively where possible. In patients taking concomitant theophylline, a theophyllineplasma concentration was also determined.

To describe the pharmacokinetics of grepafloxacin, it was necessary to obtain plasma samples at appropriate time points. In addition to the plasma trough samples obtained at clinic visits, four serum samples were obtained on either day 3,4 or 5 . These were obtained at predose, at $1 \mathrm{~h}$ after grepafloxacin administration, at $2 \mathrm{~h}$ after grepafloxacin admini- stration, and at least $1 \mathrm{~h}$ after the third sample but within $12 \mathrm{~h}$ after the dose. In total, the typical patient had eight samples obtained at $0,72,73,74,77,168,240$ and $336 \mathrm{~h}$. The times when these samples were obtained were based on optimal sampling theory (11-13) applied to previous data in normal volunteers $(14,15)$.

Sputum was collected by the patients over the $24 \mathrm{~h}$ before their clinic visits. Volume was measured, and an aliquot was analyzed for cell numbers and cell types. Culture was used to identify organisms, and a quantitative Gram stain analysis was performed to determine the number of organisms $(14,16)$. If a respiratory pathogen or predominant organism was isolated from a sample, bacterial susceptibility to grepafloxacin was determined as an MIC. From daily measurements of these specimens, the time to eradication of bacteria from pulmonary excretions, bacterial response, inflammatory response and clinical response were determined. Additional measures of disease resolution were made using the sputum neutrophil levels and clinical data including frequent evaluations of bronchopulmonary symptoms.

Drug assay: Plasma samples were analyzed for grepafloxacin by high pressure liquid chromatography.

Pharmacometric modelling methods: A population pharmacokinetic model was fitted to the plasma concentration versus time data. All grepafloxacin data from each subject were comodelled. This included the trough plasma samples obtained from all clinic visits and the four plasma samples obtained on clinic days 3,4 or 5 . The individual and population parameter values were determined by the iterative two-stage analysis $(13,16)$. The model is illustrated in Figure 1.

Identification of factors predictive of grepafloxacin pharmacokinetics: An initial statistical screen of the effects of age, race, sex, weight, smoking history, alcohol use, laboratory values, pulmonary diagnosis, dose, clinical study site, concomitant medications (eg, theophylline) and active medical problems on the pharmacokinetics of grepafloxacin was performed by classification and regression tree (CART) analysis, a procedure that uses recursive partitioning; multiple, stepwise linear regression $(17,18)$ and the Kruskal-Wallis nonparametric, one-way analysis of variance (17).

Modelling the pharmacodynamics of response: Three measures of antimicrobial response were modelled: probability of a bacteriological cure, probability of a clinical cure and time (days of treatment) until eradication of bacteria from pulmonary secretions. Probability of cure was initially modelled using both multifactorial and stepwise logistic regression (19), and CART (18). Then, certain relationships were modelled using a Hill-type pharmacodynamic model (1). The time to bacterial eradication was modelled using proportional hazards regression (20).

The independent variables evaluated were the same for all three measures of antibacterial response. Variables included the bacterial species and MIC, and the patient's age, pulmonary diagnosis (eg, chronic bronchitis, chronic bronchial asthma, bronchiectasis), other active medical problems, concomitant drugs, laboratory values and clinical site of treatment. 
TABLE 1

Summary of selected exposure covariates for pharmacodynamic response

\begin{tabular}{|c|c|c|c|c|c|}
\hline & $\mathbf{n}$ & Mean & Coefficient of variance $\%$ & Median & Range \\
\hline AUC & 119 & 15.4 & 92 & 10.0 & $2.59-69.8$ \\
\hline AUICmp & 119 & 762 & 233 & 242 & $6.46-14,765$ \\
\hline Peak & 76 & 1.60 & 65 & 1.36 & $0.398-4.54$ \\
\hline Peak/MICmp & 119 & 96.5 & 291 & 24.2 & $0.705-2589$ \\
\hline Trough & 76 & 0.357 & 86 & 0.255 & $0.003-1.27$ \\
\hline Trough/MICmp & 119 & 20.7 & 258 & 5.10 & $0.0447-430$ \\
\hline MICmp & 119 & 0.211 & 226 & 0.0450 & $0.001-3.0$ \\
\hline
\end{tabular}

For peak and trough, the number of cases ( $n$ ) is the number of patients. For area under the curve (AUC) (AUCO to DTE /days to eradication) and measures related to minimum inhibitory concentration (MIC), $n$ is the number of bacterial strains isolated. AUIC Area under the inhibitory curve: mp Midpoint

The independent variables also included the following measures of drug exposure: dose (mg/day), the $24 \mathrm{~h}$ area under the plasma concentration versus time curve, the AUIC (AUC:MIC), the peak plasma concentration achieved on day 5 (peak), the ratio of peak:MIC, the trough following the fifth dose (trough), the trough:MIC and the percentage of time that plasma concentrations were above the MIC (during the fifth dose interval).

\section{RESULTS}

Demographics and distribution of assigned doses: Seventy-six patients ( 43 males, 33 females) were randomly assigned to once daily, oral grepafloxacin dosage regimens (27 patients were given $200 \mathrm{mg}, 24$ patients $400 \mathrm{mg}$ and 25 patients $600 \mathrm{mg}$ ).

The median (range) weight was $74 \mathrm{~kg}$ (41 to $129 \mathrm{~kg}$ ) and age was 63 years (23 to 81 years). All patients except one were Caucasian. A total of 617 grepafloxacin plasma concentrations were obtained in these 76 patients; the median (and mean) was eight samples, with a range between two and 12 samples per subject.

Fitted pharmacokinetic parameter values: The model used to fit the pharmacokinetic data is illustrated in Figure 1. The $\mathrm{AUC}_{\text {average }}$ was computed by simulating the plasma concentration profiles that would be achieved by giving $600 \mathrm{mg} / 65 \mathrm{~kg} /$ day for seven days. The $\mathrm{AUC}_{\text {average was obtained }}$ by numerically integrating the $\mathrm{AUC}_{0}$ to 7 days and dividing by seven, thus yielding the $24 \mathrm{~h}$ AUC, averaged over days 1 through 7 . The fitted pharmacokinetic parameter values for all 76 patients were provided earlier (10). Neither age, sex, dose nor study site (race was not assessed because 75 of 76 patients were Caucasian) were significant predictors of the pharmacokinetics of grepafloxacin.

Pharmacodynamic response: Table 1 presents a summary of the exposure covariates developed out of the integration of the pharmacokinetics with the MIC - the pharmacokinetic/pharmacodynamic analysis. For peak and trough, the number of cases $(n)$ is 76 , the number of patients. These values were obtained from the 'intensively reconstructed' (simulated) fifth dose interval. For AUC ( $\mathrm{AUC}_{0}$ to DTE [days to eradication] $/ \mathrm{DTE}$ ) and the measures related to MIC, $\mathrm{n}$ is 119 , the number of bacterial strains isolated.
As can be appreciated from the data in Tables 1 and 2, there was substantive interpatient variance in AUC (eg, coefficient of variance $[\mathrm{CV}] \%=92)$, peak $(\mathrm{CV} \%=65)$ and trough $(\mathrm{CV} \%=86)$ concentrations, and even larger variance in MICmp (midpoint $\mathrm{MIC})(\mathrm{CV} \%=226)$ and the measures that are related to $\mathrm{MICmp}$ (AUICmp, peak/MICmp and trough/MICmp). In addition, for six of 119 bacterial isolates, the plasma concentrations were above the MICmp for less than $10 \%$ of the day; for 17 of 119 isolates, the time above the MICmp was $55 \%$ to $60 \%$; and, for 96 of 119 isolates, the trough was above the MICmp, so the time above the MICmp was $100 \%$.

Pharmacodynamics of antibacterial response - Univariate analyses: Table 3 presents a univariate statistical summary of the apparent relationship between AUIC and the probability of bacteriological and clinical cure. For bacteriological cure, there were 119 evaluable strains in 69 patients (Figure 2), and, for clinical cure, there were 90 evaluable strains in 59 patients (Figure 3). Probabilities of bacteriological and clinical cure suggest that the probability of clinical cure was higher with a 600 versus a $200 \mathrm{mg}$ dose $(\mathrm{P}<0.005)$.

When response was partitioned by bacterial species and AUICmp, it could be appreciated that Pseudomonas aeruginosa and Staphylococcus aureus had lower probabilities of both bacteriological and clinical cure. Most of the species differences in AUICmp were a consequence of species differences in MICmp. For both microbiological and clinical cure, there was a decreasing probability of cure with increasing MICmp (Table 2).

Tables 2 and 3 present activity measures that integrate the pharmacokinetics with the potency (eg, MIC) of the drug. All of the factors tested (percentage of time above the MICmp, AUICmp, peak:MICmp and trough:MICmp) covaried strongly, and all exhibited a trend for increasing likelihood of cure with increasing activity. AUICmp was the 'best ' (most predictive of outcome) of these variables (Table 3).

Multivariate analyses: Probability of cure and time to eradication are complex functions, usually dependent on a number of factors. Obtaining an optimal assessment of the factors that affect antibacterial response requires integration of the antibiotic dosage regimen and pharmacokinetics (to determine exposure profile) with the susceptibility of the bacteria to the drug (eg, as reflected by MIC). Then, these and other factors should 


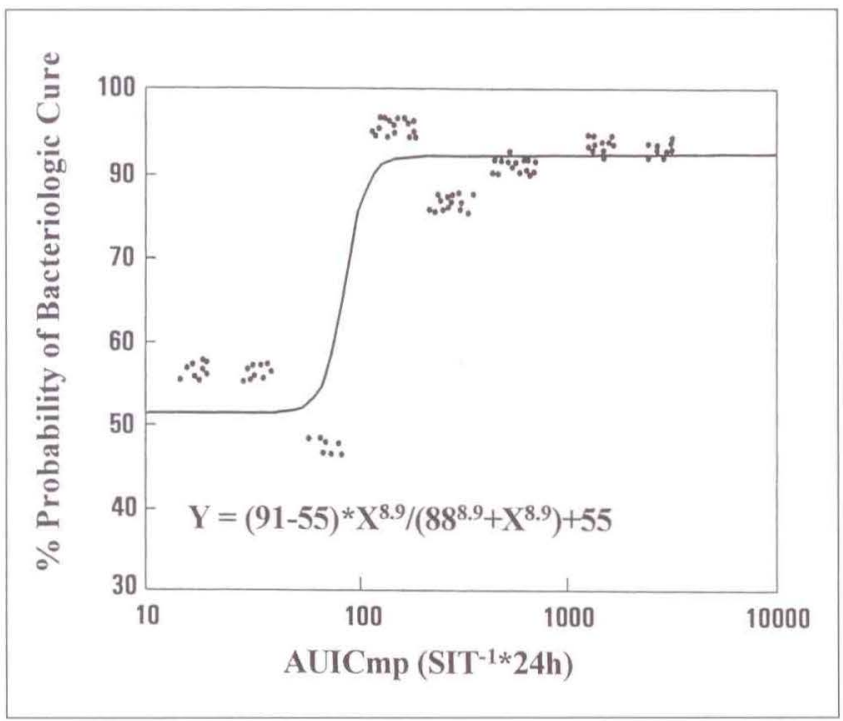

Figure 2) Jitter plot of the Hill-type pharmacodynamic models for the percentage probability of bacteriological cure versus the midpoint area under the inhibitory curve (AUICMp). The equations at the bottom of the plots and the curves depict the fitted model. The $x$-axis is log transformed only for purposes of graphical clarity. No transformations were employed in the analyses. SIT Serum inhibiting time

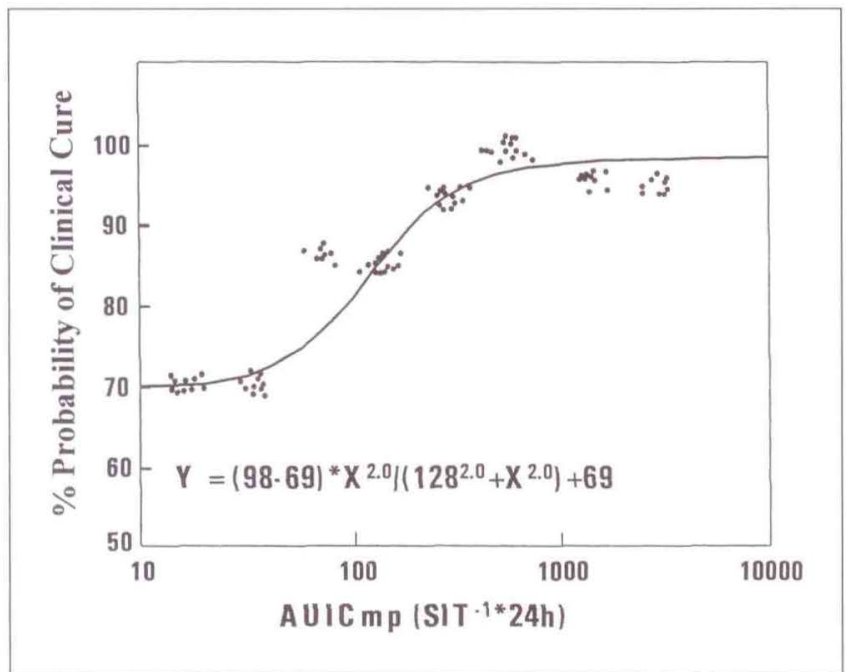

Figure 3) Jitter plot of the Hill-type pharmacodynamic models for the percent probability of clinical cure versus the midpoint area under the inhibitory curve (AUICmp). The equations at the bottom of the plots and the curves depict the fitted model. The x-axis is log transformed only for purposes of graphical clarity. No transformations were employed in the analyses. SIT Serum inhibiting titre

be considered simultaneously, using the appropriate multivariate methods of analysis.

When multivariate, stepwise logistic regression and a recursive partitioning procedure (CART) were used to determine covariates to the probability of bacteriological and of clinical cure, both methods indicated that AUICmp was the most important determinant of response. For probability of bacteriologic cure, there was a single breakpoint, at an AUICmp of $92 /$ serum inhibiting titre (SIT) $\times 24 \mathrm{~h}$ (an AUIC of 69). Below this limit, 20 of $35(57 \%)$ strains were eradicated, and, above
TABLE 2

Results of univariate analyses: Relationships of bacteriological and clinical cure to study variables

\begin{tabular}{|c|c|c|c|}
\hline Parameter & $n$ & $\begin{array}{c}\% \text { Bacteriological } \\
\text { cure }\end{array}$ & $\%$ Clinical cure \\
\hline \multicolumn{4}{|l|}{ Dose (mean [CV\%]) } \\
\hline $200 \mathrm{mg} \mathrm{q} 24 \mathrm{~h}$ & 27 & $73(44)$ & $65(34)$ \\
\hline $400 \mathrm{mg} \mathrm{q} 24 \mathrm{~h}$ & 24 & $85(40)$ & $87(30)$ \\
\hline $600 \mathrm{mg} \mathrm{q} 24 \mathrm{~h}$ & 25 & $85(34)$ & $96(25)$ \\
\hline \multicolumn{4}{|l|}{$M I C(n)$} \\
\hline $0.0-0.1$ & & $92(77)$ & $97(58)$ \\
\hline $0.11-0.2$ & & $65(23)$ & $53(15)$ \\
\hline $0.21-0.4$ & & $56(5)$ & $75(8)$ \\
\hline $0.41-0.8$ & & $100(3)$ & $100(3)$ \\
\hline $1.4-3.0$ & & $17(6)$ & $17(6)$ \\
\hline \multicolumn{4}{|c|}{$\%$ Time above MIC (n) } \\
\hline$<10 \%$ & & $40(5)$ & $75(4)$ \\
\hline$>10<100 \%$ & & $53(17)$ & $64(14)$ \\
\hline $100 \%$ & & $88(96)$ & $92(72)$ \\
\hline \multicolumn{4}{|l|}{ Peak/MICmp (n) } \\
\hline $0-2$ & & $50(10)$ & $78(9)$ \\
\hline $2.1-4$ & & $70(10)$ & $56(9)$ \\
\hline $4.1-8$ & & $46(13)$ & $78(9)$ \\
\hline $8.1-16$ & & $92(12)$ & $78(9)$ \\
\hline $16.1-32$ & & $84(19)$ & $92(12)$ \\
\hline $32.1-2589$ & & $93(54)$ & $98(42)$ \\
\hline
\end{tabular}

CV Coefficient of variance; MIC Minimum inhibitory concentration; $n$ Number of organisms tested

TABLE 3

Results of univariate analyses: Relationship of bacteriological and clinical cure to study variables

\begin{tabular}{lcc}
$\begin{array}{l}\text { Parameter } \\
\text { AUICmp }(\mathbf{n})\end{array}$ & $\begin{array}{c}\text { \% Bacteriological } \\
\text { cure }\end{array}$ & \% Clinical cure \\
\hline $0-50$ & $61(28)$ & $70(23)$ \\
$51-100$ & $50(8)$ & $86(7)$ \\
$101-200$ & $95(19)$ & $85(13)$ \\
$201-400$ & $84(19)$ & $93(14)$ \\
$401-800$ & $89(19)$ & $100(14)$ \\
$801-14,765$ & $92(25)$ & $94(19)$
\end{tabular}

AUIC Area under the inhibitory curve; mp Midpoint; $n$ Numbers of organisms tested

an AUICmp of 92, 75 of 83 strains (90\%) were eradicated. For probability of clinical cure, two breakpoints, at an AUICmp of 92 and at a value of 230 (an AUIC of 173), were identified. Below an AUICmp of 92, 20 of 28 evaluable strains (71\%) were associated with clinical cure; at an AUICmp between 92 and 230, 12 of 15 strains (80\%) were cured; and, at an AUICmp greater than 230, 45 of 46 strains (98\%) were associated with a clinical cure.

With AUICmp in the model, none of the other drug exposure measures (eg, dose, peak, peak:MIC, AUC and time above 


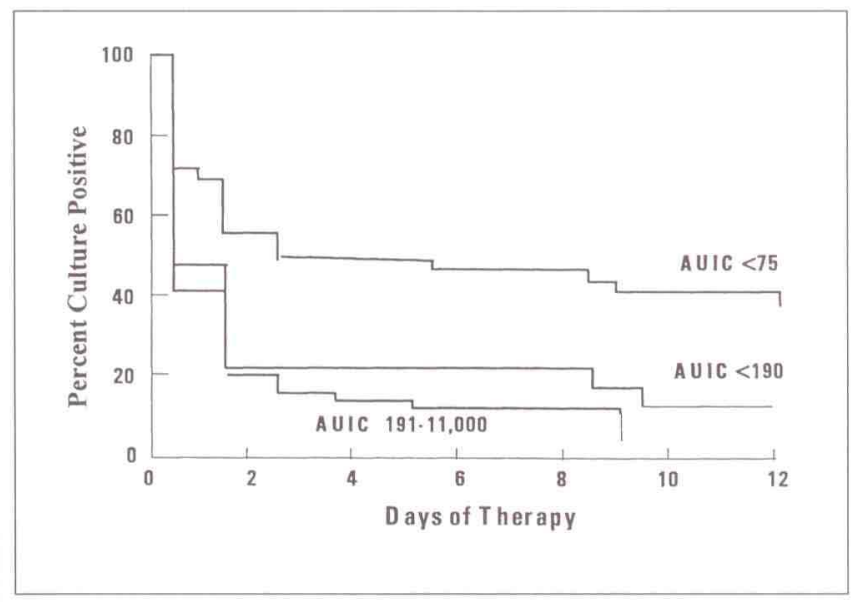

Figure 4) Kaplan-Meier plots of rates of eradication (117 bacterial strains in 76 acute bacterial exacerbations of chronic bronchitis patients). The three areas under the in hibitory curve (AUIC) ranges (AUIC less than $75, n=36$ strains; AUIC between 75 and $190, n=23$ strains; AUIC between 190 and $11,000, n=58$ strains) for which rate of eradication differed (AUIC between 190 and 11,000 versus AUIC less than 75 and AUIC between 75 and 190, P<0.001; AUIC between 75 and 190 versus AUIC between 190 and 11,000 differed from 3.5 to 8.5 days, $P<0.05)$ are depicted.

the MIC) nor MIC, infection site, or others provided any additional information.

The last pharmacodynarnic measure modelled was the days to eradication of bacteria from the sputum. Proportional hazards analysis was performed on 117 evaluable strains in 76 patients. Again, of all of the potential covariates, AUIC was the most informative, and, once AUIC was in the model, no other factor was significant. Figure 4 shows the Kaplan-Meier plots for the percentage of strains remaining culture positive (vertical axis) versus days of therapy (horizontal axis), with each different AUIC range marked. After consolidating the AUIC regions that did not differ, three curves remained. At an AUIC below $75(n=36)$, the median time to eradication (DTE $50 \%$ ) was 2.5 days, and the time to eradication of $75 \%$ of strains (DTE $75 \%$ ) was infinity (at an AUIC of 75 , the predicted proportion of strains eradicated was $55 \%$; even extrapolating beyond the study period, more than $25 \%$ of strains would be predicted to remain culture positive). At an AUIC from 75 to 190 and at an AUIC greater than 190, the DTE $50 \%$ was 0.5 days, and the DTE $75 \%$ was 1.5 days. The first curve differed overall from the second two $(\mathrm{P}<0.001)$. The second two curves did not differ overall $(0.05<\mathrm{P}<0.1)$ but did differ over the period of 3.5 to 8.5 days $(\mathrm{P}<0.05)$.

\section{DISCUSSION}

Overall, grepafloxacin performed well in $\mathrm{ABECB}$ patients, from both a pharmacokinetic and clinical perspective. Considering that this agent is primarily excreted as metabolites, the pharmacokinetics were reasonable for a diverse group of patients with a wide range of age and underlying diseases. There was no evidence that the drug was subject to saturable metabolic clearance because AUC was linear with dose. Grepafloxacin is characterized by incomplete bioavailability, yet the serum profiles varied little between patients. On average, the serum concentrations exceeded the MIC for at least a part of the dosing interval in virtually all ABECB patients. There were problem MIC values for this agent, as is typical of previously studied fluoroquinolones and other classes of antibiotic.

Population pharmacodynamics: Probability of cure and days of treatment needed to eradicate bacteria from the sputum were highly dependent on the AUIC. In univariate analyses, other measures of exposure were also significantly related to outcome but none more strongly than AUIC. Considering all three models of pharmacodynamics, it would appear that organisms will not be eradicated with an AUIC less than $75 / \mathrm{SIT} \times 24 \mathrm{~h}$ (an AUICmp of 100) during treatment of ABECB patients. An AUIC from 75 to 175 (AUICmp from 100 to 230) will be effective, but an AUIC greater than 175 is optimal because it produces more rapid killing of the organism. No concentration-effect relationships have been identified for grepafloxacin toxicity, so the upper end of the optimal exposure is, in part, an empirical value. Also, risk of toxicity to the patient is most likely associated with AUC, not AUIC. These AUIC breakpoints are lower than the 125/SIT that we had recommended for patients with nosocomial LRTI who were being treated with ciprofloxacin (1). These differences are most likely due to differences in the immunocompetence of the patient, not differences in pharmacodynamics between the two quinolones.

Because there was little additional benefit to AUIC values greater than 175 , considering interpatient variance in pharmacokinetics and cost efficiency, we recommend targeting an AUIC of $350 /$ SIT $\times 24 \mathrm{~h}$, when possible (eg, not exceeding an AUC associated with an unacceptable risk of gastrointestinal disturbance).

Grepafloxacin, 400 to $600 \mathrm{mg}$ daily as monotherapy, was able to eradicate organisms with MIC values 0.25 to $0.5 \mu \mathrm{g} / \mathrm{mL}$. For organisms with an MIC of $0.5 \mathrm{mg} / \mathrm{mL}$, only $33 \%$ could be expected to have organism eradication with a grepafloxacin regimen of $600 \mathrm{mg}$ daily. Longer courses of therapy can also be considered. For an MIC of $0.5 \mathrm{mg} / \mathrm{mL}$, the predicted microbial failure rate (40.3\%) for $600 \mathrm{mg} / 65 \mathrm{~kg} /$ day when given for five days is almost $33 \%$ higher than after 10 days of therapy $(31.2 \%)$. At an MIC of $0.25 \mathrm{mg} / \mathrm{mL}$ or less, a regimen of 600 $\mathrm{mg} / 65 \mathrm{~kg} /$ day provides significantly faster eradication and a better probability of cure. In patients who cannot tolerate this regimen, $400 \mathrm{mg} / 65 \mathrm{~kg} /$ day for longer courses can provide acceptable cure rates. One possible exception is bacterial species. In our previous work, in patients with nosocomial LRTI receiving a different fluoroquinolone, no species-specific differences in response versus AUIC were noted (1). It is possible that the tendency of Pseudomonas aeruginosa to require higher doses to effect bacterial eradication could be an effect of ABECB, or pseudomonas could be a marker of more severe pulmonary involvement and, thus, an indirect measure of disease response.

All of these conclusions are based on a therapeutic goal of initial bacterial eradication, a situation that has been well predicted by models of the relationships between pharmacokinetics as AUC and the organism MIC. In nosocomial pneumonia, failure to eradicate the organism leads to continued infection symp- 
toms, organism resistance and clinical failure (1-5,21,22). In nosocomial pneumonia, organism eradication is a prerequisite to cure. This may or may not apply to patients with $\mathrm{ABECB}$, where it appears that disease resolution is more common even when the antibiotic is not active against the isolated organism $(8,23)$. Based on studies in nosocomial pneumonia,

\section{REFERENCES}

1. Forrest A, Nix DE, Ballow $\mathrm{CH}$, Goss TF, Birmingham MC, Schentag JJ. Pharmacodynamics of intravenous ciprofloxacin in seriously ill patients. Antimicrob Agents Chemother 1993:37:1073-81.

2. Goss TF, Forrest A, Nix DE, Ballow $\mathrm{CH}$, Birmingham $\mathrm{MC}$, Cumbo TJ, Schentag JJ. Mathematical examination of dual individualization principles (II): The rate of bacterial eradication at the same area under the inhibitory curve (AUIC) is more rapid for ciprofloxacin than for cefmenoxime. Ann Pharmacother 1994;28:863-8

3. Peloquin CA, Cumbo TJ, Nix DE, Sands W, Schentag IJ. Evaluation of intravenous ciprofloxacin in patients with nosocomial lower respiratory tract infections. Impact of plasma concentrations, organism, minimum inhibitory concentration, and clinical condition on bacterial eradication. Arch Intern Med 1989;149:2269-73.

4. Schentag JJ, Nix DE, Adelman MH. Mathematical examination of dual individualization principles (I): Relationships between AUC above MIC and area under the inhibitory curve for cefmenoxime, ciprofloxacin, and tobramycin. DICP 1991;25:1050-7.

5. Hyatt JM, McKinnon PS, Zimmer GS, Schentag JJ. The importance of pharmacokinetic/pharmacodynamic surrogate markers to outcome. Focus on antibacterial agents. Clin Pharmacokinet 1995;28:143-60.

6. Nix DE, Schentag JJ. The quinolones: an overview and comparative appraisal of their pharmacokinetics and pharmacodynamics. J Clin Pharmacol 1988;28:169-78.

7. Chodosh S. Treatment of acute exacerbations of chronic bronchitis: state of the art. Am J Med 1991;91(Suppl 6A):87S-92S.

8. Ball P. Epidemiology and treatment of chronic bronchitis and its exacerbations. Chest 1995;108(2 Suppl):43S-52S.

9. Lillington GA. Bronchitis, a primary care update. Consultant 1993;33(Suppl 9):34-8.

10. Forrest A, Chodosh S, Amantea MA, Collins DA, Schentag JJ. Pharmacokinetics and pharmacodynamics of oral grepafloxacin in patients with acute bacterial exacerbations of chronic bronchitis. J Antimicrob Chemother 1997:40(Suppl A):45-57.

11. D'Argenio DZ, Schumitzky A. A program package for simulation resistance selection is also predicted in situations where $A B E C B$ patients do not have bacterial eradication (21). Even selected resistance in this patient population may not be associated with clinical failure, but the selection of resistance could result in a slower resolution of disease and, potentially, crosstransmission of resistant organisms to other patients.

and parameter estimation in pharmacokinetic systems Comput Programs Biomed 1979;9:115-34.

12. D'Argenio DZ, Schumitzky A. Adapt II users guide. Los Angeles: University of Southern California Biomedical Simulations Resource, 1992.

13. Forrest A, Hawtoff, J, Egorin MJ. Evaluation of a new program for population PK/PD analysis: applied to simulated phase I data. Clin Pharmacol Ther 1991;49:153.

14. Chodosh S, Eichel B, Ellis C, Medici TC. Comparison of trimethoprim-sulfamethoxazole with ampicillin in acute infectious exacerbations of chronic bronchitis: a double-blind, crossover study. Rev Infect Dis 1982;4:517-27.

15. Prévost $G$. Estimation of a normal probability density function from samples measured with non-negligible and non-constant dispersion, Internal Report 6-77. Adersa-Gerbios: Palaiseau, 1977.

16. Baigelman W, Chodosh S, Pizzuto D, Sadow T. Quantitative sputum gram stains in chronic bronchial disease. Lung 1979;156:265-70.

17. Wllkinson L. SYSTAT: The System for Statistics. Evanston: SYSTAT, Inc, 1990

18. Steinberg D, Colla P. CART: A supplementary module for SYSTAT. Evanston: SYSTAT, Inc, 1992

19. Steinberg D, Colla P. LOGIT: A supplementary module for SYSTAT. Evanston: SYSTAT, Inc, 1991.

20. Steinberg D, Colla P. SURVIVAL: A supplementary module for SYSTAT. Evanston: SYSTAT, Inc, 1988.

21. Thomas JK, Forrest A, Bhavnani SM, Hyatt JM, Cheng A, Ballow $\mathrm{CH}$, Schentag JJ. Pharmacodynamic evaluation of factors associated with the development of bacterial resistance in acutely ill patients during therapy. Antimicrob Agents Chemother 1998;42:521-7

22. Hyatt JM, Schentag JJ. Risk factors for selection of Pseudomonas aeruginosa resistance to Ciprofloxacin in patients with previously susceptible strains. 6th Annual Meeting of SHEA, the Society for Healthcare Epidemiology of America, Washington DC, April 21-23, 1996. (Abst 56)

23. Trigg CJ, Davies RJ. Antibiotic prescribing for bronchitis: time for a change? Respir Med 1994;88:161-3. 


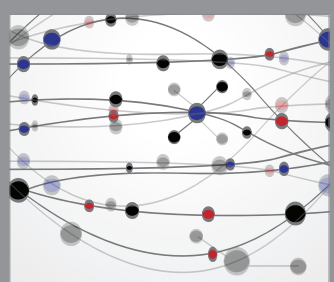

The Scientific World Journal
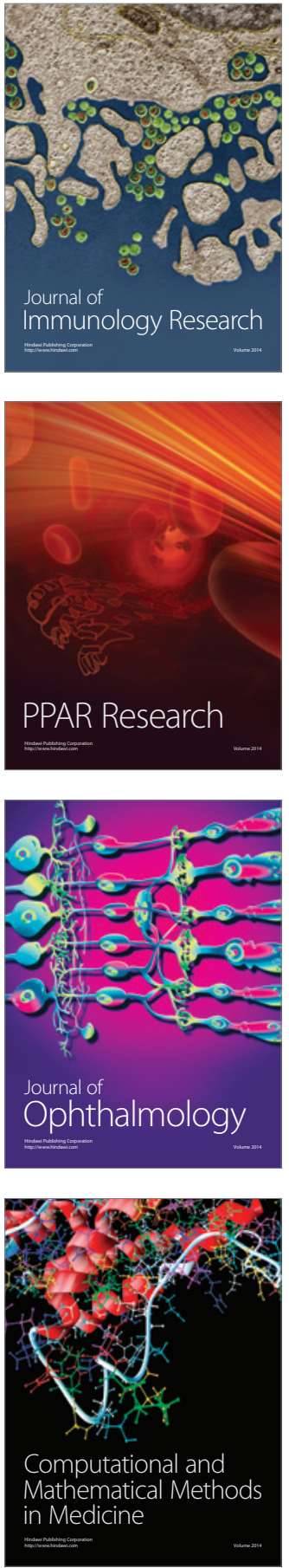

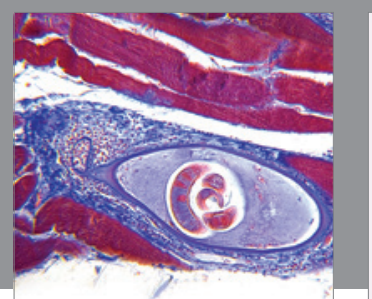

Gastroenterology Research and Practice

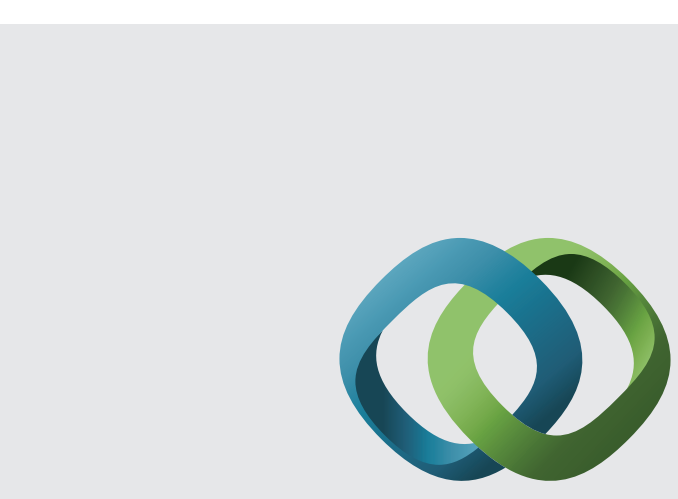

\section{Hindawi}

Submit your manuscripts at

http://www.hindawi.com
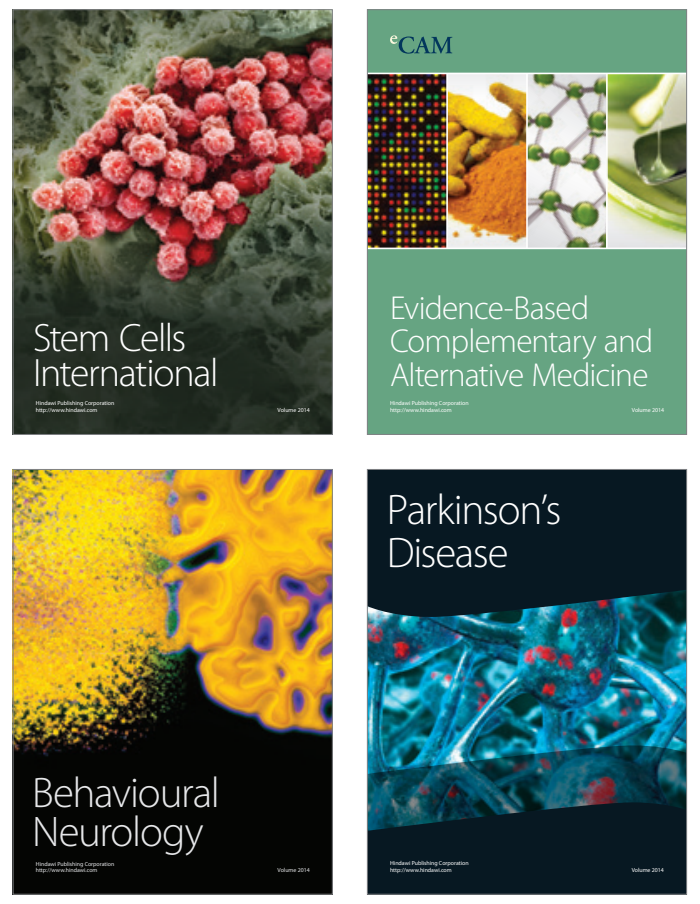
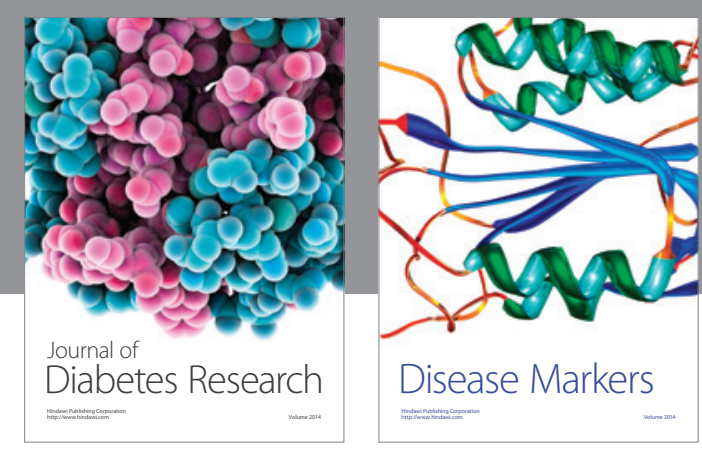

Disease Markers
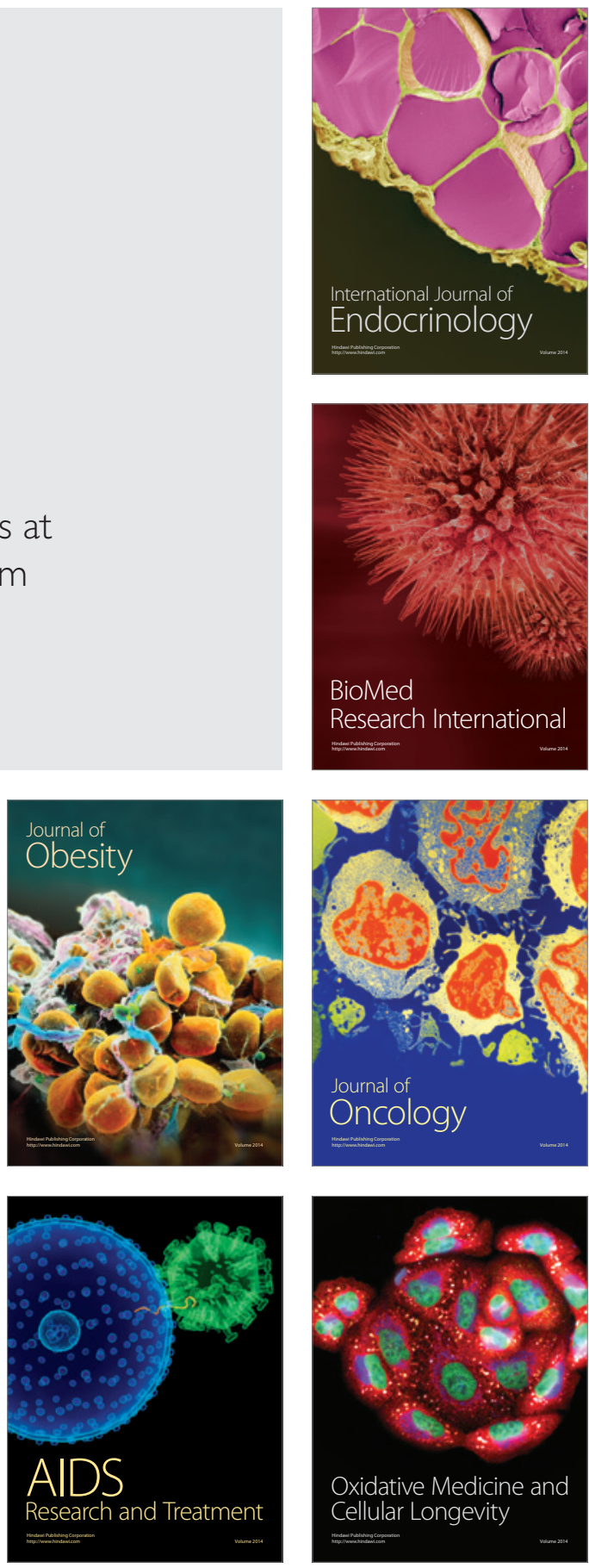